\title{
Planejamento na Organização do Trabalho Pedagógico Escolar no ensino remoto
}

\author{
Planning in the Organization of School \\ Pedagogical Work in Remote Education
}

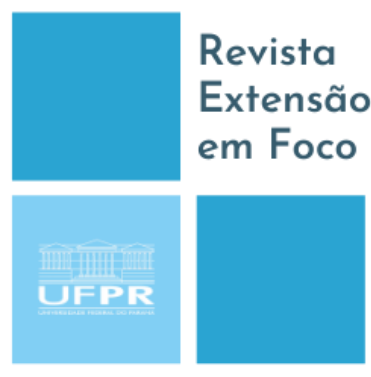

ISSN 2358.7180

\section{Léia de Cássia Fernandes Hegeto ${ }^{1}$, Yan Soares da Silva² ${ }^{2}$, Rafaela Dias ${ }^{3}$}

\begin{abstract}
RESUMO
Esta pesquisa tem como objetivo refletir sobre a importância do planejamento na prática pedagógica e docente no cenário da pandemia. As atividades realizadas no âmbito do Projeto de Extensão Universitária "Planejamento na Organização do Trabalho Pedagógico Escolar", ocorreram a partir de atividades remotas, visto a pandemia da COVID-19. O projeto promove a aproximação entre estudantes das Licenciaturas da Universidade Federal do Paraná (UFPR) e profissionais de uma escola pública de Curitiba/PR, contemplando a tríade Ensino, Pesquisa e Extensão. Com a suspensão das atividades presenciais, a pesquisa passou a ser realizada de forma remota. Buscou-se refletir sobre a prática de planejamento e organização docente, alinhando-se aos aportes teóricos previstos pelo projeto. Acreditase que analisar o planejamento em situações adversas possibilita reflexões que impactem o modo como os professores e licenciandos planejam suas aulas. Como resultados pode-se afirmar a importância de estudos que tenham como foco o sentido e uso do planejamento escolar. Foram produzidos durante as atividades remotas estudos sobre os temas, reuniões, produção de lives e criação de conteúdos audiovisuais para as redes sociais do projeto. Conclui-se que o planejamento norteia o trabalho docente e deve estar pautado por uma intencionalidade a fim de alcançar uma educação justa e de qualidade.
\end{abstract}

Palavras-chave: Planejamento Escolar. Trabalho Pedagógico. Formação de Professores.

\section{ABSTRACT}

This research aims to reflect on the importance of planning in pedagogical and teaching practice in the pandemic scenario. The activities carried out under the university extension project "Planning in the Organization of School Pedagogical Work", occurred from remote activities, since the pandemic of COVID-19. The project promotes the approach between students of the Undergraduate Studies of the Federal University of Paraná (UFPR) and professionals from a public school in Curitiba/PR, contemplating the triad Teaching, Research and Extension. With the suspension of face-to-face activities, the research started to be carried out remotely. It was sought to reflect on the practice of planning and teaching organization, aligned with the theoretical contributions provided by the project. It is believed

\footnotetext{
${ }^{1}$ Doutorado em Educação. Universidade Federal do Paraná (UFPR), Curitiba, Paraná, Brasil. E-mail: leiahegeto@hotmail.com. Orcid: https://orcid.org/0000-0002-1388-9561

${ }^{2}$ Graduação em Pedagogia. Universidade Federal do Paraná (UFPR), Curitiba, Paraná, Brasil. E-mail: yansoaressilva44@gmail.com. Orcid: https://orcid.org/0000-0003-0534-3689

${ }^{3}$ Graduação em Pedagogia. Universidade Federal do Paraná (UFPR), Curitiba, Paraná, Brasil. E-mail: fdiasrafaela@gmail.com. Orcid: https://orcid.org/0000-0003-4158-4906
} 
that analyzing the planning in adverse situations enables reflections that impact the way teachers and students plan their classes. As result one can affirm the importance of studies that focus on the meaning and use of school planning. During the remote activities were produced studies on the themes, meetings, production of lives, and creation of audiovisual content for social networks of the project. It is concluded that planning guides the teaching work and should be guided by intentionality to achieve a fair and quality education.

Keywords: School Planning. Education Work. Teacher Training.

\section{INTRODUÇÃO}

O Projeto de Extensão Planejamento na organização do trabalho pedagógico escolar tem como ponto de partida a reflexão contínua sobre o sentido e uso do planejamento para os pedagogos e professores que atuam no colégio parceiro do projeto, o Colégio Estadual Roberto Langer Júnior, situado no bairro Boqueirão na cidade de Curitiba/PR.

Durante o período de pandemia, da Covid-19, não está sendo possível a aproximação presencial dos extensionistas com as escolas públicas. Diante desse novo cenário e exigências, a equipe do Projeto de Extensão da Universidade Federal do Paraná (UFPR) procurou ajustar-se às atividades no formato remoto, mantendo as atividades no formato virtual. Buscou-se promover debates e reflexões e, assim, alcançar alunos da graduação, pedagogos e professores externos à UFPR. Os estudos sobre sentido e uso do planejamento na ação docente tiveram como foco o planejamento como possibilidade de reflexão e comprometimento com a prática.

As atividades realizadas durante esse período, possibilitaram a aproximação dos estudantes da universidade com a vivência dos professores e pedagogos da Rede Estadual de Ensino, nesse período de construção de estratégias para a ação docente. Os encontros promoveram reflexões aos profissionais da educação sobre suas práticas cotidianas. As atividades de interação com caráter dialógico se efetivaram pela interdisciplinaridade, comprometidas à concretização do tripé Pesquisa, Ensino e Extensão para os alunos das Licenciaturas da UFPR.

Do mesmo modo, defende-se que é imprescindível refletir sobre os conhecimentos didático-pedagógicos na formação de professores e por considerar a discussão sobre o planejamento escolar e de ensino necessária ao enfrentamento dos desafios do trabalho e prática escolar. Verifica-se que há, atualmente, lacunas no que se refere a pesquisas que 
tratem especificamente sobre o planejamento escolar e de ensino e sobre os conhecimentos didáticos e pedagógicos na formação do aluno da licenciatura.

Sabemos que os anos de 2020 e 2021 têm apresentado grandes desafios tanto para o ensino escolar quanto para o ensino não-escolar.

Com a pandemia, priorizou-se no Projeto de Extensão estudos de temáticas sobre o planejamento por parte dos professores e por parte dos pedagogos das redes de ensino e as medidas possíveis de serem tomadas no acompanhamento dos educandos. Em março de 2020, foi instituída a Resolução 891/2020, que passava o sistema educativo presencial para o trabalho remoto. Tal resolução visa alcançar providências para enfrentar as circunstâncias da saúde pública, causadas pelo Coronavírus - COVID19 (PARANÁ, 2020).

O Projeto de Extensão prevê a necessidade da interação dialógica e relação teoria e prática entre os conhecimentos ensinados nos cursos de formação inicial de professores. As condições para se efetivar o processo de ensino-aprendizagem se reconfiguraram no período remoto. Nessa perspectiva, o planejamento por parte da equipe pedagógica e docente é necessário para a construção coletiva de estratégias didáticas e metodológicas às exigências do momento.

O planejamento escolar de ensino precisou ser organizado de maneira que priorizasse o atendimento das necessidades e peculiaridade dos estudantes, condição indispensável na tentativa de se concretizar um bom trabalho. Por exemplo, a adequação realizada aos alunos que receberam os conteúdos por meio de atividades impressas, recebidas quinzenalmente na escola. Portanto, se a prática escolar presencial exige o planejamento constante e a contextualização das ações, as aulas remotas exigirão ainda mais.

Verificou-se que a organização dos conteúdos e metodologias de ensino pode se constituir em um desafio para muitos professores. Principalmente, em relação ao planejamento, tendo em vista as angústias e práticas atuais que podem contribuir tanto para permanência e sucesso dos alunos quanto para a exclusão e fracasso escolar.

Buscou-se a discussão sobre o uso do planejamento, justamente por se considerar essa temática imprescindível na formação inicial e continuada do professor. No Projeto 
de Extensão, parte-se do pressuposto de que o planejamento pode contribuir com a efetivação de um ensino de qualidade que contemple a diversidade cultural e as necessidades individuais dos sujeitos, compreendidos enquanto sujeitos de direitos.

\section{MÉTODOS}

O estudo é de natureza qualitativa, constituindo-se como uma pesquisa exploratória (bibliográfica) e pesquisa descritiva (coleta de dados via formulários do Google Drive). A pesquisa envolveu a criação de lives e materiais audiovisuais para as páginas nas redes sociais do Projeto de Extensão.

Visto a necessidade de não enfraquecer os debates sobre o planejamento, foi planejado o cronograma das ações remotas para o período letivo de 2020 apresentadas a seguir. O ponto de partida foi verificar como tem ocorrido as relações entre os sujeitos escolares (professores, alunos, pedagogos) e os conhecimentos. Nos encontros quinzenais foram abordadas temáticas como: elaboração de planejamentos, objetivos e finalidade do ensino, seleção dos conteúdos, metodologias de ensino, formas de avaliação, relação professor e aluno, planejamento do espaço e tempo escolar, participação na elaboração do Projeto Político-Pedagógico (PPP) e do regimento escolar, dentre outras temáticas relevantes.

O trabalho tem por fundamento o conceito de escola Justa, traçado por François Dubet (2004). Procurou-se identificar como a escola e os professores têm planejado a busca pela garantia de uma escola mais equânime, especialmente no período remoto. Foram elaborados materiais audiovisuais para serem usados com a comunidade acadêmica e com os profissionais da educação básica. Foram tratados os principais referenciais teóricos, que discutem sobre o planejamento e as contribuições dos conhecimentos didático-pedagógicos na formação e prática de professores. Esses materiais foram produzidos pelos estudantes do projeto, na plataforma Adobe Spark ${ }^{1}$.

Como parte do desenvolvimento das atividades do projeto no período remoto, foi criado um canal no YouTube para divulgação dos materiais audiovisuais elaborados pelos alunos extensionistas. O canal tem se dedicado a produzir conteúdos teóricos sobre os 
tipos de planejamento de uma maneira acessível, objetiva e esclarecedora. Nesse sentido, percebeu-se que as redes sociais, para além das publicações no Youtube - Facebook e Instagram-, constituíram-se como ferramentas importantes para a difusão de conteúdo, com enfoque no planejamento escolar e ensino.

Foi realizada uma pesquisa de campo, de cunho quantitativo e qualitativo, com os professores do colégio parceiro. A coleta de dados foi realizada por meio do formulário no Google Forms ${ }^{2}$ direcionada aos profissionais do colégio. As questões do formulário se referem à adaptação dos professores ao ensino remoto, ao relacionamento entre professor-professor, professor-aluno, professor-Gestão Escolar, entre outros temas.

A vantagem da utilização do Google Forms para a pesquisa, seja ela acadêmica ou de opinião, é a praticidade no processo de coleta das informações. O criador do formulário pode enviar o link para os respondentes via e-mail, sendo possível responder de qualquer lugar, ou tipo de equipamento. Outras vantagens do Google Forms, é que as respostas podem ser organizadas em forma de gráficos e planilhas, proporcionando um resultado quantitativo, facilitando assim, a análise dos dados.

Após a realização da pesquisa de coleta de dados pelo Google Forms iniciou-se a produção das lives. No início da pandemia, a popularização das transmissões em tempo real, somado às facilidades de alcance ao público por meio das mídias digitais, motivou o projeto a adotar as lives transmitidas pelo YouTube na plataforma StreamYard ${ }^{3}$. As lives se constituem como possibilidade de espaço para reflexão, formação e diálogo sobre os desafios vivenciados pelos profissionais da educação neste momento de ensino remoto.

As oportunidades comunicativas a distância incentivam a interação dos pares envolvidos, que por meio dos comentários, curtidas, respostas, reações e compartilhamentos se construiu o trabalho desenvolvido nas lives, gerando engajamento social dos sujeitos envolvidos no processo. Nesse sentido, concordamos com LUPINACCI (2020, p. 5), que ao delimitar teoricamente o sentido da transmissão em tempo real nessas novas configurações sociais, diz que "o ao vivo é antes de mais nada uma construção, que precisa ser 'trazida à vida' através da articulação de capacidade técnica, intencionalidade, e sentido".

No ano de 2020, foram planejadas e realizadas três lives transmitidas no Youtube. A primeira live realizada no mês de julho foi intitulada Planejamento em tempos de 
pandemia. Foram convidadas três profissionais do colégio parceiro- duas professoras e a diretora auxiliar, para dialogar sobre os desafios vivenciados neste momento sob a ótica do planejamento. Na entrevista às convidadas, construímos perguntas geradoras para encaminhar a discussão. As perguntas tiveram como objetivo compreender as vivências da organização do planejamento orientado pelos encaminhamentos da Secretaria de Estado da Educação e do Esporte (SEED/PR) e suas adaptações construídas para a adequação à realidade.

A segunda live, que ocorreu no mês de agosto, teve como título Roda de conversa com estudantes da UFPR: o Planejamento na Educação em debate. Para compor a discussão, o evento contou com a participação dos alunos do Projeto de Extensão. Foram tratadas questões relacionadas aos tipos de planejamento atrelado ao contexto das demandas organizacionais da educação no período.

Na mesma perspectiva, a terceira live, no mês de outubro, intitulada Diálogos entre estudantes da UFPR: O Planejamento Escolar a partir de diferentes perspectivas, teve como pauta discutir temas relacionados aos resultados e as respostas, coletadas na pesquisa do Google Forms. A discussão abordou os tópicos: Gestão Democrática Conselho de classe e Conselho escolar; Políticas de Estado para a manutenção do ensino remoto; Integração das tecnologias e mídias digitais na educação; Formação docente para atuação com as tecnologias; Interações pessoais no ensino remoto; Avaliação da aprendizagem e Educação especial.

Foram organizadas também reuniões on-line abertas em dezembro de 2020. Dessa maneira, o convite se encaminhou aos participantes de forma mais direcionada. A mudança para a plataforma Jitsi, que permite a participação interativa, foi estratégica ao perceber que o uso de lives já estava se tornando desgastante para o público em relação ao início do período remoto em que as lives eram uma novidade, tendo uma participação expressiva.

Contudo da euforia inicial de participar e estar em diferentes encontros com seus ídolos, sejam acadêmicos, artísticos, influenciadores digitais, vemos emergir um desgaste e cansaço. Cansaço, frente ao dilúvio de informações que são veiculadas e não conseguimos administrar cognitivamente e desgaste, pois a frequência de lives foi surpreendente, ocorrendo muitas vezes simultaneamente, na qual a audiência precisa escolher o que vai ouvir naquele momento e como hesita (ALMEIDA e ALVES, 2020, p. 5). 
Uma reunião que teve como título: Atividades do projeto de Extensão Planejamento na OTP foi direcionada aos profissionais do colégio parceiro - diretores, pedagogas e professores -, com o objetivo de ser uma reunião de primeiro contato do projeto de extensão com todo o corpo docente e pedagógico. Foram apresentados os objetivos do projeto, as atividades remotas desenvolvidas durante o ano e formação acerca da conceitualização teórica sobre o planejamento escolar e de ensino Assim como, foi priorizada a abertura e participação aos profissionais para dialogarem com os extensionistas sobre as vivências do planejar no período remoto.

$\mathrm{Na}$ última atividade de 2020, organizou-se a reunião on-line Trocando experiências. O evento teve a temática do planejamento escolar e de ensino. Os presentes foram incentivados a participar de uma dinâmica de planejamento pessoal chamada Roda da Vida, na qual se refletiu sobre o âmbito pessoal, profissional, em relação a qualidade de vida e relacionamentos pessoais. A discussão contou com a participação de estudantes das Licenciaturas, de diversas instituições e estados do Brasil.

A partir destas atividades realizadas durante o ano foi possível conhecer o conjunto de saberes utilizados pelo professor na sua prática profissional. Para Tardif (2005) é preciso conhecer os saberes docentes incorporados pelos professores que são: saberes profissionais, disciplinares, curriculares e experienciais Sobre a natureza dos conhecimentos didáticos-pedagógicos, pode-se afirmar que são aqueles conteúdos voltados aos processos de ensino e aprendizagem.

\section{DISCUSSÕES E RESULTADOS}

As reuniões com os extensionistas contribuíram para o aprofundamento dos estudos, a partir da fundamentação teórica e diálogos constantes entre os extensionistas. Nas discussões realizadas, partiu-se da defesa que o planejamento por parte do pedagogo e professor é essencial na qualidade e no atendimento das turmas e dos alunos, especialmente neste período de ensino remoto. Em relação à participação dos alunos dos colégios públicos, sabe-se que nem todos os alunos têm conseguido acompanhar as aulas remotas em função de várias questões, como por exemplo, a falta de acesso à internet 
e/ou aos equipamentos como notebook e computadores. Muitos alunos têm utilizado o celular dos pais e/ou responsáveis para acompanhar as aulas.

As reuniões evidenciaram também a necessidade de encontrar alternativas e caminhos possíveis para a oferta de um ensino comprometido com a formação e o desenvolvimento dos estudantes, especialmente neste período de instabilidade e incertezas. Em um período de incertezas, Morin (2001) diz que as certezas são uma ilusão, e temos que aprender a conviver com o desconhecimento sobre o futuro. "A chegada do Coronavírus nos lembra que a incerteza permanece um elemento inexpugnável da condição humana". (MORIN, 2020).

Com o isolamento social imposto pela pandemia, o planejamento das aulas por parte dos professores teve que ser flexibilizado, assim como a participação em cursos e eventos pedagógicos deixaram de acontecer presencialmente. Muitos profissionais da educação tiveram que se adaptar a um novo formato de educação on-line que ocasionou para muitos professores e pedagogos uma grande sobrecarga de trabalho, dificuldades no acesso e uso das tecnologias, multiplicando as tarefas e burocratizando as atividades.

Foram evidenciadas dificuldades relacionadas às condições socioeconômicas, emocionais e de aprendizagem, principalmente quanto à escuta das opiniões dos alunos em relação às aulas. Os resultados indicam a atuação dos professores na tentativa de se aproximar dos alunos e assim tentar diminuir as desigualdades escolares causadas pelas desigualdades sociais. Buscou-se a oferta e garantia de um mínimo escolar a todos os estudantes. A atuação a partir dessas intencionalidades é necessária quando se busca construir uma escola mais justa.

Defende-se tal como afirma Vasconcellos (2019) que o planejamento na educação consiste no processo de organizar e coordenar ações pedagógicas de forma articulada com a realidade intra e extraescolar. $\mathrm{O}$ ato de planejar busca visar a reflexão racional e didática sobre as ações educativas com a finalidade de atingir um objetivo.

Uma alternativa de aproximação com a realidade da escola foi a utilização da ferramenta Google Forms foi direcionada aos professores e aos pedagogos do colégio parceiro. O Google Forms tem ampliado as possibilidades educacionais e contribuído com a aprendizagem colaborativa, favorecendo a interação, a troca de ideias e a produção coletiva de textos. 
São apresentadas a seguir os resultados das 4 questões respondidas por 12 profissionais (professores e pedagogos) no Google Forms:

1) Eu tenho planejado as minhas aulas neste período de pandemia?

2) Atuo com consciência dos objetivos da educação na sociedade atual?

3) Eu conheço bem as condições socioeconômicas dos meus alunos?

4) Escuto as expectativas e opiniões dos alunos em relação ao andamento das aulas e as levo em conta?

5) Participo de oficinas e eventos pedagógicos on-line.

Na primeira questão: Eu tenho planejado as minhas aulas neste período de pandemia? Ao serem questionados se estão planejando suas aulas, 75\% afirmou que sempre planeja, $16,7 \%$ que às vezes e $8,3 \%$ que a partir do aplicativo Aula Paraná ${ }^{4}$ (aulas transmitidas a toda a Rede Estadual de Ensino via TV aberta ou internet). Os dados mostram a importância do planejamento, pois para Vasconcellos (2019), para ser transformadora, a prática deve ser intencional, por isso a necessidade do planejamento, para que se saiba de onde se parte e o que desejamos alcançar.

Compreende-se que o acúmulo de atividades e a complexidade de se planejar neste contexto tem sido um grande dificultador do trabalho, porém, como aponta Vasconcellos (2019), uma das finalidades do planejamento é ajudar a superar dificuldades. Considera-se que ao planejar o professor, também mobiliza conhecimentos didático-pedagógicos e que eles são como uma ponte entre os conhecimentos aprendidos nos cursos, ou seja, os conhecimentos de referência e entre os conhecimentos escolares. Os conhecimentos didático-pedagógicos auxiliam o professor na sua prática além da sala de aula. Ensinar deve ter como base conhecimentos que se constituem como essenciais na formação docente.

Entende-se que a falta de planejamento pode aumentar as desigualdades, assim como planejar baseando-se em aulas generalizadas, pré formatadas que não contemplam as diferenciações entre escolas, salas e estudantes. Neste momento, o Planejamento é uma possibilidade para tentar garantir uma escola justa, diversificada e inclusiva. 
Na segunda questão: Atuo com consciência dos objetivos da educação na sociedade atual? 58,3\% identificaram que sempre atuam com consciência, e $41 \%$ relataram que somente às vezes. Com isso, foram identificadas questões relacionadas à construção e dificuldades na realização do planejamento em tempos de pandemia, tendo em vista os desafios postos no período, quanto aos conhecimentos a serem ensinados, quanto à formação dos professores e adequação à proposta curricular.

Na terceira questão: Eu conheço bem as condições socioeconômicas dos meus alunos? Nesta questão, 16,7\% dos professores afirmam que conhecem as condições e $83,3 \%$ dos professores afirmam que ocasionalmente conhecem as condições socioeconômicas dos alunos. É importante conhecer os alunos e as condições que possuem para executar e elaborar um planejamento coerente e justo. Dubet (2004) afirma que "para obter mais justiça, seria preciso, portanto, que a escola levasse em conta as desigualdades reais e procurasse, em certa medida, compensá-las." (DUBET, 2004. p. $545)$.

Essa reflexão e conhecimento sobre a realidade do aluno implica em exercer a profissão de forma consciente, reconhecer que o sistema não é totalmente justo, pois embora dentro da escola, aparentemente todos tenham a mesma oportunidade, o que muda é o ponto de partida desse aluno, que vai ser formado pelas oportunidades e condições que o aluno possui fora da escola, e neste período a escola não consegue garantir igualdade de oportunidades, visto que ela não mais controla o ambiente de estudo e nem o tempo dedicado a ele. É preciso considerar essas variáveis na formulação das atividades, buscando explorar as diferenças a seu favor.

Na quarta questão: Escuto as expectativas e opiniões dos alunos em relação ao andamento das aulas e as levo em conta? $75 \%$ relatou que sempre escuta e $25 \%$ às vezes. Ao falar sobre o planejamento, Vasconcellos (2019) aponta que o uso de estratégias para engajar o aluno nas aulas ajudam a manter o vínculo com o aluno e essa é uma atitude que favorece o trabalho do professor. A prática docente tem uma dimensão coletiva e a explicitação da proposta de trabalho por parte do professor é fundamental na articulação sistemática e crítica por parte do aluno (VASCONCELLOS, 2019). 
Ao observar que os professores procuram na maioria das vezes ouvir seus alunos, percebe-se a necessidade de que o planejamento coincida melhor com a realidade e faça desta forma mais sentido para os alunos, obtendo assim mais participação em sala de aula.

Na quinta questão: Participo de oficinas e eventos pedagógicos on-line. A metade, ou seja, $50 \%$ dos educadores têm por hábito sempre participar de eventos de forma remota e $41,7 \%$ participam de vez em quando e somente um pesquisado respondeu que não acessa essas plataformas de oficinas on-line.

A formação continuada de professores é entendida como um processo permanente de aperfeiçoamento dos saberes necessários à atividade profissional, deve ser buscado constantemente por pedagogos e professores.

Nessas cinco questões ficou evidente que as tecnologias digitais têm assumido um papel importante no ensino, pois permitem um processo de interação, estimulam o diálogo, a criatividade e autonomia dos sujeitos de maneira colaborativa e compartilhada, em diferentes tempos e espaços. "Numa abordagem colaborativa as tarefas são realizadas por todos num contínuo de partilha, diálogo e negociação" (BARROSO e COUTINHO, 2009, p. 14).

Em suma, a pesquisa encontrou em seus resultados que a identidade do professor é algo de relevância ao ser discutido, demonstrando que o ser educador está em constante evolução e transformação. O planejamento tem-se revelado importante na formação continuada e na observação de prática pedagógica, buscando tornar-se um educador crítico e reflexivo.

Buscou-se articular os formulários utilizados na pesquisa com as lives e eventos produzidos. No qual, nas lives produzidas sempre ressaltou-se as adversidades que os educadores enfrentam em seu cotidiano, relacionado às possibilidades de trabalho com um bom planejamento escolar e de ensino.

$\mathrm{Na}$ primeira live, com a participação das educadoras do colégio parceiro, foi possível explorar e compreender como a escola estava lidando com as adversidades nos primeiros meses de pandemia. Foi salientado durante a primeira live que para acompanhar o modelo de ensino remoto é necessário acesso, equipamentos, autonomia intelectual por parte dos estudantes. Infelizmente esse acesso e aprendizagem não tem acontecido com 
todos os estudantes que acompanham as aulas on-line, pela faixa etária e outras limitações que acontecem por diferentes razões, tais como condições de vida que fogem da vontade do estudante e da família.

Apresentou-se na live, que não dá para discutir o planejamento nesses tempos de pandemia sem refletir a proposta da Rede Estadual de Ensino do Paraná. Com aulas online (gravadas, tele aulas em canais abertos, aulas no Google Classroom, Whatsapp, entrega de atividades impressas na escola, etc) que colocam em risco a vida dos profissionais da escola e as próprias famílias.

Enfim, há que se reconhecer que tem ocorrido nesse modelo de aulas on-line, um excesso de atividades sem que ocorra o tempo necessário de planejamento, percebe-se que muitas vezes tem se priorizado a quantidade em relação a qualidade do trabalho. Visto que o planejamento é imprescindível para uma boa prática docente, foi realizado a segunda live teve o objetivo de contribuir apresentando os planejamento escolar e de ensino para a formação inicial e continuada dos educadores.

$\mathrm{Na}$ segunda live, com a participação de mais de 200 (duzentas pessoas), os extensionistas apresentaram os diversos tipos de planejamento: Plano Nacional de Educação (PNE), Plano de Ação Escolar, Plano de Ação do Pedagogo, Projeto Político Pedagógico (PPP) Proposta Pedagógica Curricular (PPC), Currículo da Rede Estadual Paranaense (CREP), Plano de Trabalho Docente (PTD), Plano de aula.

Foi frisado que planejar é uma atividade inerente ao trabalho do professor, que exige um trabalho de reflexão sobre o ensino e sobre a aprendizagem dos estudantes. Vasconcellos (2019) afirma que o planejamento é instrumento de transformação da realidade. Os extensionistas ressaltaram que o planejamento, mental ou escrito, impessoal ou formal pode ser visto como elemento de práxis, mediação metodológica que ajuda a fazer a aproximação teoria e prática.

Planejar é pensado como um processo (e não como ato isolado, pontual, sem sentido a que ele que o realiza). Uma das funções básicas do planejamento é a produção de sentido na prática docente. Com essa ideia de planejar como produzir sentido, veio a terceira e última live, com 190 (cento e noventa) participantes. Os extensionistas ficaram livres para buscar temáticas e apresentá-las. As temáticas são: Gestão democrática: conselho de classe e conselho escolar. Formação docente para atuação com as tecnologias. Integração 
das tecnologias e mídias digitais na educação. Interações pessoais no ensino remoto. Avaliação da aprendizagem. Educação Especial.

Verificou-se a partir das lives que o planejamento na educação procura atingir objetivos educacionais a médio e longo prazo, fazendo-se de forma contínua, tornandose um referencial entre o objetivo final e o processo para que se alcance essa meta. Esse planejamento também abrange a definição de problemas, desafios e prioridades no ensino, para que de maneira racional e organizada se concretize uma educação inclusiva, de qualidade e igualitária tanto nas condições de acesso como na trajetória. Nessa perspectiva Libâneo (2001), afirma que o planejamento é um processo contínuo de conhecimento e análise da realidade escolar em suas condições concretas, busca de alternativas para soluções de problemas e de tomada de decisões.

Portanto, nas lives ficou explícito que a organização dos conteúdos e metodologias de ensino pode se constituir em um desafio para muitos professores, especialmente neste período de Pandemia. Principalmente, em relação ao planejamento, tendo em vista as angústias e práticas atuais que podem contribuir tanto para permanência e sucesso dos alunos quanto para a exclusão e fracasso escolar.

As investigações e pesquisas atuais da área pedagógica expressam o propósito de identificar e analisar conhecimentos e princípios que mediatizam a relação teoria e a prática no trabalho diário do professor. Na tentativa de não haver dicotomia na relação teoria e prática deve ocorrer o envolvimento necessário entre o aluno e o conhecimento construído na relação com o professor e os colegas de sala.

Em relação a esse envolvimento, André e Oliveira (1997, p. 21) afirmam: "Parto do princípio de que os conhecimentos são construídos por meio da ação e da interação. Assim, o sujeito aprende quando se envolve ativamente no processo de produção de conhecimentos através da mobilização das suas atividades mentais e da interação com o outro, mediada pela linguagem.

\section{CONSIDERAÇÕES FINAIS}


As atividades realizadas pelos extensionistas a partir da construção de lives, questionários, materiais audiovisuais, estudos teóricos e aproximação com o colégio parceiro, demonstrou que é fundamental, refletir sobre temáticas que se constituem como necessárias na formação dos licenciandos. Portanto, defende-se que ocorra no interior das escolas discussões frequentes sobre o planejamento, como possibilidade de superar os desafios e as dificuldades encontradas por professores e pedagogos no processo de ensino aprendizagem e organização do trabalho escolar.

Neste período de pandemia, ficou evidente que é preciso investir em um dos objetivos iniciais propostos pelo projeto de extensão, que é relacionar a teoria e prática na formação inicial dos alunos extensionistas. Os referenciais teóricos sobre o planejamento de ensino e escolar ajudaram a pensar em possibilidades de enfrentamento da pandemia. Mostrou-se possível enfrentar as dificuldades de ensino-aprendizagem com um bom planejamento, por isso o planejamento coletivo e interdisciplinar deve ser adotado como prática cotidiana na escola.

Em suma, defende-se que o ensino remoto da forma como está sendo ofertado na Rede Estadual de Ensino no Paraná é uma forma de atendimento emergencial que implica em grandes desafios a todos os envolvidos. As dificuldades ocorrem principalmente em relação ao acesso de professores, pedagogos e alunos, em relação à participação e aprendizagem dos alunos e o excesso e burocratização do trabalho.

É importante manter a resiliência, a generosidade e a perseverança na construção de uma escola mais justa reconhecendo a Pedagogia como uma ciência e os professores e pedagogos como especialistas da área pedagógica. Salienta-se o significativo papel do planejamento na prática docente e o papel dos educadores nas modalidades de planejamento (escolar e ensino). Acredita-se que é necessário continuar lutando por melhores condições de trabalho e respeito às individualidades e necessidades de cada sujeito escolar, entendidos aqui como sujeitos de direitos.

\section{NOTAS}

1. Adobe Spark é uma plataforma que permite aos usuários criar imagens e vídeos curtos para as redes sociais. 
2. O formulário Google Forms é uma ferramenta gratuita de criação de formulários on-line, disponível para qualquer usuário que possui uma conta no Google e ainda pode ser acessado em diversas plataformas, inclusive, por meio do celular.

3. Uma plataforma que permite a realização de lives de até seis pessoas com transmissão no YouTube.

4. No período da pandemia de Covid-19, os estudantes da rede pública podem assistir às aulas por meio de um aplicativo e em canais de TV vinculados à RIC, afiliada da Rede Record no Paraná.

\section{REFERÊNCIAS}

ALMEIDA, Beatriz Oliveira de; ALVES, Lynn Rosalina Gama. Lives, educação e Covid-19: Estratégias de interação na pandemia. Revista Interface Científica - Educação, Bahia, v. 10, p. 149-163, set. 2020. Disponível em: https://periodicos.set.edu.br/educacao/article/view/8926/4135. Acesso em: 31 de março de 2021.

ANDRÉ, Marli Eliza Dalmazo Afonso de; OLIVEIRA, Maria Rita Neto Sales. Alternativas no ensino de didática. [S.l: s.n.], 1997.

BARROSO, Marta; COUTINHO, Clara. Utilização da ferramenta Google Docs no Ensino das Ciências Naturais: um estudo com alunos do $8^{\circ}$ ano de escolaridade. Revista Iberoamericana de Informática Educativa. Espanha, n.9, jan-jun 2009, p. 10-21.

DUBET, François. O que é uma escola justa? Caderno de Pesquisa. v. 34, n123, p.539555. set./dez. 2004.

LIBÂNEO, José Carlos. Organização e Gestão da Escola - teoria e prática. 5 ed. Goiânia: Alternativa, 2001.

LUPINACCI, Ludmila. "Da minha sala pra sua": Teorizando o fenômeno das lives em mídias sociais. Scielo Preprint, 2020. Disponível em: https://preprints.scielo.org/index.php/scielo/preprint/download/960/2207/2315. Acesso em: 31 de março de 2021. 
MORIN, Edgar. As certezas são uma ilusão. Fronteiras do pensamento. 9 abr. 2020. Entrevista. Disponível em: https://www.fronteiras.com/entrevistas/edgar-morin-as certezas-sao-uma-ilusao. Acesso em: 16 de mar. 2020.

MORIN, Edgar. Por uma reforma do pensamento. In: O pensar complexo: Edgar Morin e a crise da modernidade. Nascimento, Elimar Pinheiro do; Pena-Veja, Alfredo (orgs.). 3a ed. Rio de Janeiro: Garamond, 2001.

PARANÁ. Secretaria de educação e do esporte (SEED). Resolução $\mathbf{N}^{\circ} \mathbf{8 9 1}$, de 18 de março de 2020. Estabelece medidas previstas no decreto ${ }^{\circ} 4.230$, de 16 de março de 2020, e $\mathrm{n}^{\circ} 4.258$, de 17 de março de 2020, no âmbito da Secretaria do Estado da Educação e do Esporte. Diário Oficial, Paraná, n¹0649 de 19 de março. 2020.

TARDIF, Maurice; LESSARD, Claude. O trabalho docente: elementos para uma teoria da docência como profissão de interações humanas. Petrópolis: Vozes, 2005.

VASCONCELlOS, Celso dos S. Sobre o Planejamento Escolar: Momentos Iniciais, Projeto de Ensino - Aprendizagem e Trabalho por Projetos. In: Gestão da Sala de Aula. São Paulo: Libertad, 2019 (no prelo).

Recebido em: 16 de Abril de 2021. Aceito em: 11 de Maio de 2021. 